\title{
PREVALENCE OF METABOLIC SYNDROME IN ISCHEMIC HEART DISEASE PATIENTS
}

\author{
SULTANA N ${ }^{1}$, KABIR MS ${ }^{2}$, HOSSAIN MZ ${ }^{3}$, CHOWDHURY $\mathrm{J}^{4}$, BEGUM $\mathrm{S}^{5}$, DATTA R ${ }^{6}$, HOSSAIN \\ $\mathrm{SZ}^{7}, \mathrm{RAHMAN} \mathrm{MS}^{8}$
}

\begin{abstract}
Ischemic heart disease (IHD) is one of the four leading causes of death globally. An important risk factor for IHD is metabolic syndrome. The definition of metabolic syndrome is not universally agreed. The most commonly used definition was proposed by the National Cholesterol Education Program - Adult Treatment panel III ( NCEP-ATP III), where metabolic syndrome defined as involving three or more of the following criteria: Blood pressure > 130/85 $\mathrm{mm}$ of $\mathrm{Hg}$, fasting blood sugar $>100 \mathrm{mg} / \mathrm{dl}$, triglyceride level $>150 \mathrm{mg} / \mathrm{dl}$, high density lipoprotein cholesterol $(\mathrm{HDL}-\mathrm{C})<40 \mathrm{mg} / \mathrm{dl}$ in men and $<50 \mathrm{mg} / \mathrm{dl}$ in women, and abdominal circumference $>102 \mathrm{~cm}$ in men and $>88 \mathrm{~cm}$ in women.I. which is characterized by clustering of central obesity, hypertension, hyperglycemia and dyslipidemia. This cross sectional analytical study was carried out in the Department of Biochemistry, Dhaka Medical college. The samples were collected from the Department of Cardiology of Dhaka Medical College Hospital (DMCH), Bangladesh Institute of Research on Diabetes Endocrine and Metabolic Disorder (BIRDEM), and National Institute of Cardiovascular Diseases (NICVD), Dhaka, during the period from July 2009 to June 2010. Age distribution of study group shows that majority of the IHD patients with or without metabolic syndrome were in 41-60 years of age group.

In the present study the prevalence of metabolic syndrome in IHD patients was found to be $30 \%$. Prevalence was higher in less then 50 years of age group. The prevalence was also higher in female than male.
\end{abstract}

Key words: Prevalence, metabolic syndrome, ischemic heart disease.

J Dhaka Med Coll. 2014; 23(2) : 157-160.

\section{Introduction:}

A clustering of metabolic abnormalities associated with cardiovascular diseases, first described by Reaven in 1988 was also given many unsatisfactory names such as Syndrome X, Deadly Quartet, insulin resistant syndrome. ${ }^{1}$ Metabolic syndrome characterized by clustering of central obesity, hypertension, hyperglycemia, and dyslipidemia. It is important risk factor for IHD and other cardiovascular complication and is itself a cause of mortality. The definition of metabolic syndrome is not universally agreed. The most commonly used definition was proposed by the National Cholesterol Education Program - Adult Treatment panel III (NCEP-ATP III), where metabolic syndrome defined as involving three or more of the following criteria: Blood pressure $>130 / 85 \mathrm{~mm}$ of $\mathrm{Hg}$, fasting blood sugar $>100$ mg / dl, triglyceride level > 150mg / dl, high density lipoprotein cholesterol ( HDL-C) < 40mg $/ \mathrm{dl}$ in men and $<50 \mathrm{mg} / \mathrm{dl}$ in women, and abdominal circumference $>102 \mathrm{~cm}$ in men and $>88 \mathrm{~cm}$ in women. ${ }^{2}$.

The WHO Western Pacific region suggested a revised Asia- Pacific criterion (AP) for Asian population s using reduced values for both the Body Mass Index (BMI $\geq 25 \mathrm{~kg} / \mathrm{m}^{2}$ in both sexes) and abdominal waist circumference $(\geq 90 \mathrm{~cm}$ in men and $\geq 80 \mathrm{~cm}$ in women $).{ }^{2}$ The WHO defines the metabolic syndrome as requiring the presence of impaired glucose regulation or

1. Dr. Nafisa Sultana, Lecturer, Department of Biochemistry, Dhaka Medical College, Dhaka.

2. Dr. Md.Saifullah Kabir, Consultant (Surgury), Upajilla Health Complex, Melandah, Jamalpur.

3. Dr. Mohammad Zaid Hossain, Associate Professor, Department of Medicine, Dhaka Medical College, Dhaka

4. Dr. Jesmine Chowdhury, Associate Professor, Department of Biochemistry, Dr. Sirajul Islam Medical College, Dhaka.

5. Dr. Shahara Begum, Lecturer, Department of Biochemistry, Dhaka Medical College, Dhaka

6. Dr. Raj Datta, Residence Physician, Dhaka Medical College Hospital, Dhaka

7. Dr. Syed Zakir Hossain, Assistant Professor, Department of Medicine, Dhaka Medical College, Dhaka 8. Dr. Md. Saidur Rahman, Assistant Registrar, Department of Medicine, Dhaka Medical College, Dhaka Correspondence: Dr. Nafisa Sultana, Lecturer, Department of Biochemistry, Dhaka Medical College, Dhaka. 
insulin resistance and at least two risk factors among hypertension, dyslipidemia, obesity, microalbuminuria (includes individuals with and without diabetes). ${ }^{3}$ The prevalence of metabolic syndrome in Qatar is $26.5 \%$ according to ATP 222 and $33.7 \%$ IDF $(\mathrm{p}<0.001) .{ }^{4}$ The prevalence of metabolic syndrome in IHD patients in USA is $35 \% .{ }^{5}$

The prevalence has been increased with the severity of obesity and age, but decreases with higher education and physical activity. Also the prevalence of metabolic syndrome is more common in women according to ATP (61.4\%) and IDF (56.7\%). ${ }^{4} 30 \%$ of the study subjects met the criteria for metabolic syndrome among 60\% obese population in USA. ${ }^{6}$ According to IDF criteria prevalence of metabolic syndrome is $25.8 \%$ in the year 2007 and it was $30.69 \%$ at 2008 in India. ${ }^{3}$ But there is paucity of data regarding prevalence of the metabolic syndrome in Bangladesh. ${ }^{7}$ Metabolic syndrome, recognized as a major contributor to IHD risk, is increasing in prevalence at an alarming rate.

Ischemic Heart Disease (IHD) or atherosclerotic coronary artery diseases also called coronary heart diseases has become global public health problem of $21^{\text {st }}$ century because of its high prevalence and concomitant increase in risk of morbidity and premature death. By 2020, it is estimated that it will be the major cause of death in all region of the world. ${ }^{8}$

IHD result from myocardial ischemia due to imbalance between the supply and demand of the heart for oxygenated blood. There is also reduced supply of nutrient and inadequate removal of metabolites. IHD can be classified into four syndromes, a) angina pectoris, b) myocardial infarction, c) sudden cardiac death, d) chronic IHD with heart failure. ${ }^{8}$

$16 \%$ of death in Japan is a result of cardiovascular diseases, are associated with increase metabolic syndrome. Risk factors for cardiovascular disease (CVD) also have strong relation to the metabolic syndrome. ${ }^{9}$ Each component of metabolic syndrome is associated with risk of IHD. Morbidity and mortality due to metabolic syndrome in IHD increases ranging from 1.4 to 4.5 in United Kingdom. ${ }^{4}$. Both IHD and metabolic syndrome it can be prevented or delayed by early detection. Patient with these disorder have a poorer quality of life and shorter life expectancy. In the USA the prevalence of metabolic syndrome in IHD has become more then twice in the past decade. ${ }^{10}$ Hence, the present study is the first designed on one thousand Bangladeshi people to evaluate biochemical parameters in metabolic syndrome related with IHD. More over this study also designed to estimate the prevalence of metabolic syndrome in IHD.

\section{Material and Methods:}

This cross sectional, analytical study of prevalence metabolic syndrome in Bangladeshi IHD patients was carried out in the Department of Biochemistry, Dhaka Medical College, Dhaka. During the period of July 2009 to June 2010.A total numbers of 1000 IHD patients were taken. Purposive sampling was done and admitted IHD patients of CCU, DMCH, BIRDM and NICVD, Dhaka, was selected as per inclusion and exclusion criteria. After having deliberate consent from each patient, data was collected in pre-designed and pre- tested data collection sheet. Serum lipid profile and fasting blood glucose were estimated in all study population. Blood pressure was measured and recorded. The waist circumference was taken to the nearest standing horizontal circumference between the lower border of the $12^{\text {th }}$ rib and the highest point of the iliac crest on the mid-axillary line at the end of normal expiration detect central obesity. From the above data IHD patients with metabolic syndrome were diagnosed and recorded. Prevalence of metabolic syndrome in IHD patients was calculated. The prevalence in metabolic syndrome was statistically estimated.

\section{Results:}

Table- I shows prevalence of metabolic syndrome in IHD patients was 30\%. We are 95\% confident that the prevalence of metabolic syndrome in IHD lies within $27.16 \%$ to $32.84 \%$.

Table-II shows among the suffered group 45\% IHD with metabolic syndrome patients were below 50 years of age. 
Table-III shows among 840 males IHD patients $28.57 \%$ were suffering from metabolic syndrome and rest of the patients were suffering from IHD only. Among the 160 females IHD patients, about $37.50 \%$ were suffering from metabolic syndrome.

Table-IV Among the study population only 43 subjects were found to having no history of taking cigarette or any other type of tobacco. They were suffering from IHD only. But 780 subjects were current smoker or taking tobacco at the time of disease condition. Among them 300 were suffering from metabolic syndrome and rest 480 were suffering from IHD only. 177 person were past smoker and suffering from IHD but on metabolic syndrome.

Besides, figure I shows that $30 \%$ of IHD patients were suffering from Metabolic Syndrome.

\section{Table I}

Prevalence of metabolic syndrome among the IHD patient: [Study population, $n=1000$ ]

\begin{tabular}{lccc}
\hline $\begin{array}{l}\text { Total } \\
\text { subject }\end{array}$ & $\begin{array}{c}\text { IHD with } \\
\text { MetS }\end{array}$ & Frequency & $95 \%$ CI \\
\hline 1000 & 300 & $30 \%$ & $27.16-32.84 \%$ \\
\hline
\end{tabular}

Table II

Prevalence of metabolic syndrome in IHD patients in different age groups:

\begin{tabular}{lcccc}
\hline Age distribution & Totaln $=1000$ & IHD with MetS & Prevalence of 95\% CI & P-value \\
\hline Age $<50$ years & 220 & $100(45 \%)$ & $41.65-48.35$ & $<0.05$ \\
Age $>50$ years & 780 & $200(25 \%)$ & $23.45 \_26.55$ & $<0.05$ \\
\hline
\end{tabular}

Table III

Prevalence of metabolic syndrome in study group according to gender:

\begin{tabular}{lcccc}
\hline Group & Totaln=1000 & IHD with MetS & Prevalence at 95\%CI & p-value \\
\hline Male & 840 & $240(28.50 \%)$ & $27.01-30.15$ & $<0.05$ \\
Female & 160 & $60(37.50 \%)$ & $33.67-41.33$ & $<0.05$ \\
\hline
\end{tabular}

Table IV

Prevalence of metabolic syndrome of study group according to tobacco history:

\begin{tabular}{lcccc}
\hline Smoking status & Total & IHD with MetS & Prevalence at 95\% CI & p-value \\
\hline Smoker & 780 & $300(38.46 \%)$ & $36.72-40.20$ & $<0.05$ \\
Past smoker & 177 & 00 & 00 & - \\
Non smoker & 43 & 00 & 00 & - \\
\hline
\end{tabular}

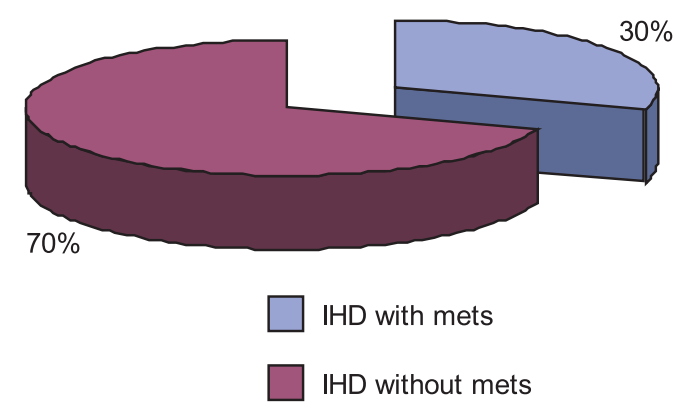

Fig-1: IHD patients suffering from Metabolic Syndrome.

\section{Discussion}

Ischemic heart disease (IHD) is one of the four leading causes of death globally. It has many epidemiologically established risk factors. An important risk factor for IHD is metabolic syndrome which is characterized by clustering of central obesity, hypertension, hyperglycemia and dyslipidemia. The predictors of metabolic syndrome are total cholesterol (TG), high density lipoprotein- cholesterol (HDL-C), body mass index (BMI), waist circumference (WC), waist hip ratio (WHR). ${ }^{11}$ - With changes of life 
style even in the developing countries the prevalence of metabolic syndrome is increasing alarmingly). ${ }^{10}$ So the present study was aimed to find out the prevalence of metabolic syndrome in IHD patients of Bangladesh. With this view 1000 IHD patients both male and female were selected as the study subjects. In this study the prevalence of metabolic syndrome were studied. The prevalence was found to be $30 \%$. Among them $28.50 \%$ was male and $37.50 \%$ was female. The same type of finding was observed by the researcher of our neighboring countries. ${ }^{5,12}$. This similarity might be due to sharing similar type of lifestyle and socioeconomic status. The study on the population of native Alaska showed the prevalence of metabolic syndrome to be $23.70 \%) .{ }^{10}$ In USA, the prevalence of metabolic syndrome estimated was as high as $35 \%) .{ }^{5}$

The prevalence of metabolic syndrome was significantly higher in female than male IHD patients in the present study. This might be due to the fact that majority of the women $(54.38 \%)$ were housewives, who were accustomed to sedentary life style. Age distribution of study group shows that majority of the IHD patients with or without metabolic syndrome were in 41-60 years of age group. This might be due the fact that people of this age group remain under psychological stress regarding their job, family and economic problem. The study of the smoking habit and tobacco use shows that all the patients of metabolic syndrome of the study group are either smoker or tobacco user or both.

\section{Conclusion}

In the present study, we found that the prevalence of metabolic syndrome in IHD patients was $30 \%$. Prevalence was higher in Â50 years of age group. The prevalence was also higher in females.

\section{References:}

1. Jamil AA, Haque KMHSS, Mamun AA, Siddique MA, Islam MN. Morphological pattern of coronary lesions in patient with cardiovascular dysmetabolic syndrome. Bangladesh J Cardiol 2009; 1(1): 40-7.
2. Oh EG, Bang SY, Hyun SS. Prevalence and clinical characteristics of metabolic syndrome for at risk people in a rural community. Metabolic syndrome and related disorders. 2009; 7(7): 11-5.

3. Dhanaraj E, Bhansali A, Jaggi S, Dutta P, Jain S, Tiwari P, et al. Prevalence and predictors of metabolic syndrome in non-obese Asian Indians with newly detected type 2 diabetes mellitus. J Indian Med Assoc 2008; 106(1): 366-72.

4. Bener A, Zirie M, Musallam, M, Khader YS, A1Hamaq AO. 2009, 'Prevalence of metabolic syndrome according to Adult Treatment Panel III and International Diabetes Federation Criteria: a population based study. Metab Syndr Relat Disord 2009; 7(3): 221-30.

5. Boudreau DM, Malone DC, Racbel MA, Fisman FA, Nichols GA, Feldstein AC, et al. Health care utilization and costs by metabolic syndrome risk factors. Metab Syndr Relat Disord 2009; 7(4): 305-14.

6. Bagby SP. Obesity initiated metabolic syndrome and the kidney: a recipe for chronic kidney disease. J Am Soc Nephrol 2004; 15(11): 2775-91.

7. Misra A, Misra R, Wijesuriya M. The metabolic syndrome in South Asians: Counting escalation and possible solution. Indian J Med Res 2007; 125(1): 345-54.

8. Bloomfield P, Bradbury A, Grubb NR, Newby DE. eds. Cardiovascular disease. In: Boon NA, Colledge NR, Walker BR, et al. eds. Davidson's principles and practice of medicine. $20^{\text {th }} \mathrm{ed}$. Philadelphia: Elsevier; 2006: p.519-646.

9. Kawada T, Okada K, Amejawa M. Component of the metabolic syndrome and life style factors in Japanese male workers. Metab Syndr Relat Disord 2008; 6(4): 263-6.

10. Schumacher C, Ferucci ED, Lanier AP, Slattery ML, Schraer CD, Raymer TW, et al. Metabolic syndrome: prevalence among American Indian and Alaska native people living in the Southwestern United states and in Alaska. Metab Syndr Relat Disord 2008; 6(4): 267-73.

11. Grundy SM, Adams-Huet B, Vega LG. Variable contributions of fat content and distribution to metabolic syndrome risk factors. Metab Syndr Relat Disord 2008; 6(4): 281-8.

12. Basit A, Shera AS. Prevalence of metabolic syndrome in Pakistan. Metab Syndr Relat Disord 2008; 6(3): 171-5. 